\title{
LA LECTURA ORIENTADA A LA COMPRENSIÓN: DIDÁCTICA Y PRÁCTICA DE LA FILOSOFÍA
}

\author{
Miguel MANDUJANO ESTRADA \\ Universidad de Barcelona, España \\ mandujano@uvaq.edu.mx
}

RECIBIDO: 10 DE FEBRERO DE 2010

ACEPTADO: 10 DE ABRIL DE 2010

Resumen: Este trabajo analiza el problema de la lectura, interpretación y comprensión de textos bajo la perspectiva de una doble vertiente: como un recurso metodológico de la enseñanza de la filosofía y como un criterio hermenéutico del acompañamiento o asesoramiento individual. Desde la consideración de la semiótica de la recepción de Umberto Eco y la hermenéutica filosófica de Hans-Georg Gadamer, propondremos las líneas generales que pudieran comunicar la dimensión didáctica y práctica del fenómeno de la lectura orientada a la comprensión.

Palabras clave: hermenéutica filosófica, semiótica de la recepción, enseñanza de la filosofía, asesoramiento filosófico o acompañamiento personalizado.

\begin{abstract}
This paper analyzes the problem of reading, interpretation and comprehension of texts under a double perspective: as a methodological resource for the teaching of philosophy and as a hermeneutical approach of accompaniment or individual counseling. From the consideration of the Umberto Eco's semiotics of reception and the Hans-Georg Gadamer's philosophical hermeneutics, we'll propose the general guidelines which could communicated didactic and practical dimension of the phenomena of reading aimed at understanding.
\end{abstract}

Keywords: Philosophical hermeneutics, Semiotics of reception, Philosophy Teaching, Philosophical Counseling or Personalized support.

\section{Premisas}

En un artículo reciente, he abordado la configuración y labor del profesor-tutor, la figura con la que la Universidad Vasco de Quiroga de Morelia ha introducido una forma de Filosofía Aplicada a la dinámica universitaria. ${ }^{1}$ Declinaré, por tanto, profundizar en ello, pero no a referir brevemente las premisas que enmarcan este trabajo.

${ }^{1}$ Cf. MANDUJANO ESTRADA, Miguel: "El acompañamiento personalizado. Notas de una 
El contexto lo constituye la presencia en la universidad de un currículo académico con contenido filosófico, transversal en todas las carreras, con un propósito institucional y fundamentalmente formativo. Los profesores adscritos al Departamento de Formación, la instancia que lo administra, son titulares de asignatura y tutores de los alumnos del grupo, esto significa que están encargados de los cursos y del acompañamiento personalizado de sus estudiantes. Esta segunda función se lleva a cabo a través de entrevistas personales, es decir, por medio de un diálogo, sin pretensiones psicologistas, orientado al análisis y a la proyección racional de la vida. Con sus particularidades, el acompañamiento o tutoría es una variante de la orientación o asesoramiento filosófico. Más aún, consideramos que el ámbito de la experiencia clase-tutoría, aunado a la labor del profesor-tutor, es más el de la Filosofía Aplicada que el de la Didáctica de la Filosofía, entre otros, porque la naturaleza de los cursos enfatiza la función práctico-formativa del conocimiento filosófico y no la sucesión temática o los objetivos cognoscitivos.

\section{Problema y propósito}

El trabajo articula las ideas del seminario La lectura orientada a la comprensión que llevamos a cabo recientemente en el Departamento de Formación de la UVAQ. En su configuración nos propusimos abordar un problema compartido por la doble función de un titular de asignatura: la lectura y análisis de textos filosóficos y el carácter que la lectura orientada a la comprensión puede adquirir si es tomada con una orientación hermenéutica como un elemento del acompañamiento individual.

Ante todo, hay que decir que no es fácil armonizar la índole de las carreras en que se imparten los programas con el desarrollo de una asignatura filosófica; las licenciaturas pertenecen en su mayoría al ámbito técnico-industrial o económico-administrativo. Esto supone la falta de habilidades propiamente filosóficas por parte de los estudiantes y una

experiencia" en BARRIENTOS RASTROJO, José (ed.): Filosofía Aplicada y Universidad, Visión Libros, Madrid, 2010. Págs. 49-70. 
distancia considerable entre la dinámica de las clases habituales y el llamado currículo formativo.

Paralelamente, y en términos generales, las dificultades de los alumnos con la filosofía se trasladan al ámbito del asesoramiento o acompañamiento individual, de manera que así como les es extraño el comentario de un texto -un recurso excepcional en la didáctica de sus carreras-, los estudiantes experimentan algunos problemas al analizar su vivencia personal y hablar de sus problemas de manera lógica $\mathrm{u}$ ordenada. Por lo demás, el ideal de formación integral enarbolado por la universidad, afronta, precisamente, paradojas como esta, proponiéndose hacer frente a las incongruencias de la sociedad y la cultura que perpetúa la educación tradicional.

\section{Lectura e interpretación}

La lectura es un principio que trasciende la identificación de caracteres y la mera interpretación de representaciones gráficas. Forma parte de una facultad humana superior. La lectura, más allá de los textos escritos, descubre una competencia asociada al reconocimiento de una estructura que nos antecede y, podríamos decir, nos da la bienvenida al mundo: La capacidad lingüística.

Desde el principio somos leídos por el otro materno e incorporados súbitamente a la dinámica de la lectura; la madre proporciona un orden primitivo al caos de sensaciones que constituye la experiencia del recién nacido, anuncia sus señales y le atribuye mensajes: Llora porque tiene hambre -dice-, e imprime sentido a los gritos del que aún no tiene palabras. $^{2}$

Por otro lado, en la lingǘstica tradicional, tanto Ferdinand de Saussure como Edward Sapir, descubrieron que la naturaleza lingüística del hombre supera el vehículo y se constituye en una capacidad fundamental, la de crear y establecer el lenguaje como una condición de acceso a las cosas. ${ }^{3}$ Esto no supone, sin embargo, la existencia de un

\footnotetext{
${ }^{2}$ Cf. REYES, Yolanda: "Un mundo de palabras habitado por el hombre", en Amigos del libro, número 28, Madrid, 1995. Págs. 27-34.

${ }^{3}$ Cf. SAUSSURE, Ferdinand de: Curso de lingüística general, Losada, Buenos Aires, 1980 [1945].
} 
universo prelingüístico, sino, como afirmará Hans-Georg Gadamer después, "un mundo orientado al lenguaje"4 que lo impregna todo y establece las condiciones de la comprensión. La lectura, la que se hace pasando la vista sobre lo escrito o impreso para comprender el significado de los caracteres empleados, supone y nos deja ver que somos seres capaces de comprensión, y que esta facultad es la que permite la interpretación de los textos pero también la interpretación en un sentido más comprehensivo, que alcanza el ámbito de las personas y, en general, el de la historia.

En adición, la lectura entraña siempre una condición dialógica, una relación necesaria entre un lector y un texto. Y viceversa, pues si escribir es crear algo que será leído, leer es una forma silenciosa de dejarse decir ese algo. Con todo, sabemos muy bien que el habla no posee una exactitud perfecta y que nunca habrá tantas palabras como ideas posibles, por eso escribir tiene siempre como meta, dice el propio Gadamer parafraseando a Fichte, forzar al otro a comprender. ${ }^{5}$ Por su lado, el otro como texto es, de la misma manera, un grito que no puede ser ignorado; así como no podemos abstenernos de leer un anuncio en la calle aunque no haya sido escrito para nosotros, no podemos deponer nuestra capacidad de comprensión ante la emergencia del otro. Podemos fingir que no hemos leído, acaso nuestra propia indolencia nos lo permita, pero no podemos, al menos, dejar de aventurar una interpretación de lo que observamos.

Finalmente, el diálogo entre un lector y un texto concluye cuando se alcanza el sentido a través de la propia interpretación. Por lo demás, "quien no capta y reproduce los textos realizando el conjunto de su articulación, modulación y estructuración, no puede, en realidad, leer."6 Es decir, no es posible leer sin comprender.

Págs. 52-58. Y SAPIR, Edward: El lenguaje. Introducción al estudio del habla, FCE, México, 1992 [1921]. Pág. 10.

${ }^{4}$ GRONDIN, Jean: Introducción a la hermenéutica filosófica, Herder, Barcelona, 1999, pág. 16.

${ }_{6}^{5}$ Cf. GADAMER, Hans-Georg: Arte y verdad de la palabra, Paidós, Barcelona, 1998. Pág. 85.

${ }^{6}$ Ibid. Págs. 76-77. 


\section{Interpretación o traducción}

El caso de la traslación entre sistemas de lenguas es un arquetipo de la interpretación y, en general, del fenómeno de la comprensión. Inclusive, Gadamer define la lectura como una traducción de una orilla a otra: de la orilla de la escritura a la del lenguaje y arriesga la paradoja "cualquier lector es un medio traductor."7

La traducción sirve a Gadamer para ilustrar la estructura de la comprensión por su afinidad esencial con la tradición, es decir, con el sentido de la historia y su conocimiento. En la traducción, nos explica, se da una relación circular entre el todo y las partes provocada por la significación anticipada de los segmentos. Es verdad, al trasladar un significado de una lengua a otra dividimos el texto en partes y postulamos el significado de las secciones, pero es sólo en la conciencia del texto completo que las piezas adquieren sentido. A la vez, si no fuera por la traslación de cada fragmento, el texto como un todo nos sería inaccesible. "Toda traducción es por eso ya una interpretación.",

La vocación de la hermenéutica es, sin duda, la comprensión, pero ésta sólo es posible logrando una suerte de acuerdo a través del diálogo lector-texto y de la relación circular a que hemos hecho referencia. En este sentido, el acuerdo de la comprensión es también conversación y nunca una suerte de descubrimiento fortuito de un sentido preestablecido. Para decirlo con Gadamer: "El sentido de la investigación hermenéutica es desvelar el milagro de la comprensión y no únicamente la comunicación misteriosa de almas. La comprensión es una participación en la pretensión común."9

Ahora bien, aunque para Gadamer la traducción es siempre una forma de interpretación, habrá que hacer una distinción, pues en realidad, la traducción llega únicamente al final de la interpretación. Umberto Eco denomina a lo que sucede en el intervalo como negociación, ${ }^{10}$ un concepto revelador que señala la suerte de convenio que se realiza entre

\footnotetext{
${ }^{7}$ Ibid. Pág. 91.

${ }^{8}$ GADAMER, Hans-Georg: Verdad y Método, Sígueme, Salamanca, 2007. Pág. 462.

${ }^{9}$ GADAMER, Hans-Georg: El problema de la conciencia histórica, Tecnos, Madrid, 1993. Pág. 98. Cursivas en el original.

${ }^{10}$ Cf. ECO, Umberto: Mouse or Rat? Translation as Negotiation, Phoenix, London, 2003. Pág. 6.
} 
dos sistemas de lengua diversos y que podemos extender al caso de las culturas, los individuos, la experiencia o las racionalidades.

Si llamamos semiosis a la totalidad las relaciones entre los procesos de significación, la verdad es que éstos pueden ser considerados una continua traducción sólo en sentido figurado. Por lo demás, la diferenciación es valiosa, ya que de otra manera podría cometerse el equívoco de postular una traducción total, vinculada con una falsa simultaneidad entre la traducción y la interpretación. Por el contrario, habría que empezar por reconocer que la traducción no supone una comprensión total, sino precisamente una traslación entre sistemas y la consideración de las particularidades de uno y otro.

Finalmente, el proceso de la comprensión se transmite a través de la mediación del lenguaje, es decir, una vez que la interpretación ha sido hecha y no de manera simultánea al pensamiento. ${ }^{11}$

Charles Sanders Peirce, una de las influencias más importantes en la obra de Eco, utiliza también el término traducción como un sinónimo de interpretación, pero estableciendo que cada equivalencia de significado entre dos expresiones se da desde la identidad de consecuencias que implican. En este sentido, el significado es la traducción de un signo en otro sistema de signos. En este caso, el término traducción es utilizado, pues, como un pars pro toto, es decir, como una sinécdoque de la interpretación. ${ }^{12}$

Al final, el énfasis que a nosotros más nos interesa es que el que considera los procesos interpretativos como intentos de comprensión de la palabra de los otros.

\section{Interpretación y sobreinterpretación}

Una de las críticas que los paradigmas interpretativos comúnmente reciben tiene que ver con la vaguedad y falta de claridad de los límites y criterios de interpretación. El problema podría ser contenido en la cuestión ¿vale todo en la interpretación?

\footnotetext{
${ }^{11}$ Cf. ECO, Umberto: Dire quasi la stessa cosa. Esperienze di traduzione, Bompiani, Milano, 2003. Pág. 231.

${ }^{12}$ Cf. Ibid. Pág. 228.
} 
Si llevamos la pregunta al ámbito del aula podríamos formularla también como ¿hasta qué punto debe el profesor permitir la interpretación, acaso poco informada, del alumno sobre un texto? $\mathrm{O}_{\text {¿En }}$ qué medida hay una verdad contenida que hay que enseñar independientemente de la comprensión del alumno?

En general, hay dos enfoques metodológicos que conducen la lectura y comentario de textos filosóficos: el enfoque generativo y el enfoque interpretativo. ${ }^{13}$ El enfoque generativo realiza el análisis del texto de manera independiente al efecto que produce en el lector. Comúnmente se sirve de herramientas histórico gramaticales y conduce a quien lee a una interpretación correcta.

En lo particular, considero que si bien hay momentos de la enseñanza que, por razones pedagógicas, requieren cierta actitud generativa, en general, el enfoque es una postura arrogante que asume que hay algo que aprender siempre y de la misma manera. La idea de educación que aquí asumimos parte de la consideración de la imposibilidad de la comprensión absoluta y el reconocimiento de factores emotivos en el proceso de la interpretación. Esta concepción afirma que es necesaria la recodificación de los saberes, la derogación de la monocultura y la afirmación del autoaprendizaje y el conocimiento recíproco. Considera que la racionalidad moderna codificó la ignorancia como caos y el saber como orden, y que el conocimiento como emancipación debe, por el contrario, establecer una trayectoria desde el colonialismo de la ignorancia hacia la solidaridad del saber ${ }^{14}$ El enfoque interpretativo, por su parte, al renunciar al objetivo fundamental de descubrir una verdad previa, es congruente con este principio, además de que su punto de partida es que no es posible tomar como objeto un texto descontextualizado, sino que éste se nos ha de presentar asociado a una serie de ideas que hagan que conocerlo signifique insertarlo en el conjunto de nuestras creencias sin romper la coherencia entre éstas.

\footnotetext{
${ }^{13}$ La distinción corresponde a BARBA LÓPEZ, Débora, et. al.: "6,26; 16,23 Apropiarse de un texto", en Diálogo filosófico, número 69, Madrid, 2007. Págs. 455-478. Este artículo realiza una propuesta para la lectura y comentario de textos filosóficos que sigue, como la nuestra, una línea hermenéutica. Por lo demás, nuestro enfoque y tratamiento de fuentes y argumentos es diverso.

${ }^{14}$ Cf. SANTOS, Boaventura de Sousa: Crítica de la razón indolente. Contra el desperdicio de la experiencia, Desclée de Brouwer, Buenos Aires, 2003. Pág. 87.
} 
En cuanto al problema de los límites o pautas de la interpretación, aludiremos a Interpretación y sobreinterpretación, ${ }^{15}$ la obra en la que Umberto Eco discute con Richard Rorty. El filósofo americano, desde un pragmatismo radical, asume que el texto puede golpearse hasta darle la forma que mejor sirva. Para Eco, en cambio, la interpretación debe conducirse con un criterio de economía que impida el extremo de la sobreinterpretación. ${ }^{16}$ Este matiz nos permitirá mediar entre las interpretaciones gratuitas y las supuestas verdades contenidas en los textos.

Hay, además, otra noción que intentaremos aplicar al caso de la lectura e interpretación de textos filosóficos, y es el concepto de obra abierta que Eco concibe en sus estudios estéticos y de comunicaciones de masas.

Para Eco, la vanguardia italiana en la década de 1960 y el arte contemporáneo en general, se caracterizan por la autonomía que conceden al intérprete y que interviene francamente en la forma de la composición. La obra abierta es aquella que no crea un mensaje categórico y acabado, sino que abre la posibilidad de varias organizaciones confiadas al intérprete. Así, las obras abiertas no son, por tanto, "obras terminadas que piden ser revividas y comprendidas en una dirección estructural dada [sino] obras abiertas que son llevadas a su término por el intérprete en el mismo momento en que las goza estéticamente." 17

De la misma manera, un texto también puede suscitar infinitas lecturas, aunque no cualquier lectura, como hemos dicho. El argumento se nutre del concepto de semiosis ilimitada del pragmatismo de Peirce y se refiere, fundamentalmente, al proceso ad infinitum que determina lo que es el interpretante de un signo por medio de otro signo. ${ }^{18}$

Además, Eco considera la presencia de un fruidor, es decir, un espectador que participa, con su propio universo cultural o enciclopedia, de la culminación de la obra. Así, Eco define la lectura como una

\footnotetext{
${ }^{15}$ Cf. ECO, Umberto: Interpretación y sobreinterpretación, Cambridge University Press, Cambridge, 1997.

${ }^{16}$ Cf. ECO, Umberto: Los límites de la interpretación, Lumen, Barcelona, 1992. Pág. 121.

${ }^{17}$ ECO, Umberto: Obra abierta, Ariel, Barcelona, 1979. Pág. 73.

${ }^{18}$ Cf. ECO, Umberto: La estructura ausente, Lumen, Barcelona, 1999. Pág. 74.
} 
transacción difícil entre la competencia del lector, es decir, su conocimiento del mundo compartido, y la competencia que un texto postula para ser leído de forma económica.

La siguiente cita es concluyente:

Cuando se embotella un texto -y esto no sucede sólo con la poesía o con la narrativa, sino también con la Crítica de la razón pura-, es decir, cuando se produce un texto no para un destinatario concreto sino para una comunidad de lectores, el autor sabe que será interpretado no según sus intenciones sino según una compleja estrategia de interacciones que implica también a los lectores, junto a su competencia de la lengua como patrimonio social. Por patrimonio social de una lengua no me refiero sólo a un conjunto de reglas gramaticales, sino también a toda la enciclopedia que se constituye a través del ejercicio de esa lengua, o sea, a las convenciones culturales que esa lengua ha producido y a la historia de las precedentes interpretaciones de muchos textos, incluido el texto que el lector está leyendo en ese momento ${ }^{19}$

\section{Autor y Lector Modelo}

El texto también es complejo por lo que no dice. La explicación de la semiosis infinita radica, en parte, en la consideración del signo como un sistema relacionado y/o un sistema de oposiciones. Por ejemplo, para Eco, la voz automóvil no se convierte en una unidad semántica en el momento en que se une al significante /automóvil/, sino desde que queda sistematizada en oposición con otras unidades semánticas, como carro, bicicleta o pie. ${ }^{20}$

Para el caso de la lectura, lo anterior supone que el lector debe actualizar su enciclopedia y un trabajo de inferencia, de manera que podemos considerar el texto como "un mecanismo perezoso (o económico) que vive de la plusvalía de sentido que el destinatario introduce en él." ${ }^{21}$ Es decir, un texto se emite para que alguien lo actualice, incluso cuando no se espera que ese alguien exista.

\footnotetext{
${ }^{19}$ ECO, Umberto: Los límites de la interpretación, ed. cit. Págs. 124-125.

${ }^{20}$ Cf. ECO, Umberto: Tratado de semiótica general, Lumen, Barcelona, 2000. Págs. 51-52.

${ }^{21}$ ECO, Umberto: Lector in fabula. La cooperación interpretativa en el texto narrativo, Lumen, Barcelona, 2000. Pág. 76.
} 
De esta manera, el texto prevé al lector, y así: "Un texto es un producto cuya suerte interpretativa debe formar parte de su propio mecanismo generativo: generar un texto significa aplicar una estrategia que incluye las previsiones de los movimientos del otro." 22 Estas previsiones toman la forma de una serie de competencias que serán capaces de dar contenido a las expresiones que utiliza, por ejemplo, mediante la elección de una lengua, de un tipo de enciclopedia, de un determinado patrimonio léxico y estilístico, de ciertos distintivos de género, de un campo geográfico, etc.

Abreviando, la previsión de un lector modelo es, en realidad, activa, en la medida en que depende de la planeación de la obra de un autor. El texto no es tan perezoso como parecía. En este sentido, el texto abierto es, en realidad, un texto cerrado.

Ahora bien, que el autor (un autor modelo puesto que la existencia del autor empírico es totalmente irrelevante) no prevea adecuadamente su lector modelo, no significa que el texto vaya a quedar abierto al goce de cualquiera, por el contrario, este último no sería un caso de cooperación sino de violencia.

Por lo anterior, la selección de los textos que se leen en clase debe ser hecha con sumo cuidado.

Distinguimos pues, entre el uso libre de un texto como estímulo imaginativo y la interpretación de un texto abierto. Por lo demás, la noción de interpretación supone una dialéctica entre la estrategia del autor y la respuesta del lector modelo. Esta distinción es, a fin de cuentas, la distinción entre una intentio operis que remite a los textos mismos para hacer sus inferencias, y una intentio lectoris en la que el lector se sirve de los textos para sus propios intereses. ${ }^{23}$

Por su parte, la labor del lector es evidente, la de hacer elecciones razonables y tomar decisiones que afectarán su ejercicio. En un texto narrativo, por ejemplo, el lector lo hace en todo momento; un texto, dice Eco utilizando una metáfora de Borges, es "un jardín cuyas sendas se bifurcan. ${ }^{24}$ Y completa: "Mientras el hablante va a terminar la frase,

\footnotetext{
${ }^{22}$ Ibid. Pág. 79. Cursivas en el original.

${ }^{23}$ Cf. ECO, Umberto: Los límites de la interpretación, ed. cit. Pág. 39.

${ }^{24}$ ECO, Umberto: Seis paseos por los bosques narrativos. Harvard University Norton Lectures $1992-$ 1993, Lumen, Barcelona, 1996. Pág. 14.
} 
nosotros, aunque sea inconscientemente, hacemos una apuesta, anticipamos su elección, o nos preguntamos angustiados qué elección hará." 25

El texto, pues, más que un parámetro para convalidar la interpretación, "es un objeto que la misma interpretación construye en el intento circular de convalidarse a través de lo que la constituye. Círculo hermenéutico por excelencia, sin duda." ${ }^{, 26}$ Esta idea nos introduce en la siguiente sección.

\section{El enfoque hermenéutico}

Las últimas afirmaciones de Eco nos introducen al universo de la hermenéutica. Sin ir más lejos, el lector modelo de su propuesta semiótica se anticipa a la elección del autor y consuma su obra, es decir, interpreta. Efectivamente, como el propio autor piamontés afirmó, la semiótica pide ser substituida por la hermenéutica. ${ }^{27}$

Ante todo, en la filosofía de Gadamer el ejercicio de la comprensión es siempre el proceso de fusión de los horizontes en juego. En la afirmación, horizonte no significa solamente desplazamiento histórico, sino un diálogo entre dos interlocutores puestos a reflexionar en conjunto y en igualdad de circunstancias. En este sentido, sigue Gadamer: "Ganar un horizonte quiere decir siempre aprender a ver más allá de lo cercano y de lo muy cercano, no desatenderlo, sino precisamente verlo mejor integrándolo en un todo más grande y en patrones más correctos. 28

No existen, pues, los horizontes cerrados, un horizonte siempre se desplaza al paso de quien se mueve, como si en la conciencia histórica este movimiento se hiciera consciente de sí mismo. De esta manera, si uno se desplaza a la situación de otro hombre, se hace consciente de su alteridad, es decir, lo comprende.

Por otro lado, en la medida en que estamos obligados a poner a prueba nuestros prejuicios, el horizonte se presenta como un proceso constante

\footnotetext{
${ }^{25}$ Ibid. Mis cursivas.

${ }^{26}$ ECO, Umberto: Los límites de la interpretación, ed. cit. Pág. 41. Mis cursivas.

${ }^{27}$ Cf. ECO, Umberto: Tratado de semiótica general, ed. cit. Pág. 253.

${ }^{28}$ GADAMER, Hans-Georg: Verdad y Método, ed. cit. Pág. 375.
} 
de formación, así, "comprender es siempre el proceso de fusión de estos presuntos «horizontes para sí mismos»" ${ }^{29}$ concluye nuestro autor.

Complementariamente, la toma de conciencia histórica tiene consecuencias para nuestro actuar espiritual y, de cierta manera, las ciencias humanas en su conjunto equivalen a un sentido histórico. De esta manera, la conciencia moderna toma como conciencia histórica una posición reflexiva en la consideración de lo que es entregado por la tradición:

"La conciencia histórica no oye más bellamente la voz que le viene del pasado, sino que, reflexionando sobre ella, la reemplaza en el contexto donde ha enraizado, para ver ella el significado y el valor relativo que le conviene. Este comportamiento reflexivo cara a cara de la tradición se llama interpretación., ${ }^{30}$

Habrá que decir también que lo que Gadamer entiende por interpretación no se reduce al terreno de los textos y la tradición verbal, sino que se extiende a todo lo que es historia. Así, para nuestro autor la hermenéutica puede hacer justicia a la historicidad de la comprensión a través del concepto de círculo hermenéutico de Heidegger.

\section{El círculo hermenéutico}

Ya habíamos adelantado el concepto cuando introdujimos la idea de traducción. Brevemente, el fenómeno de la comprensión inicia con la orientación de la mirada a la cosa por parte del observador o fruidor. En nuestro caso, este es el momento en que el lector se dirige a un texto.

La lectura, por su parte, no se realiza de manera imparcial, pues el lector lee con las expectativas de su propio horizonte y tradición. Los prejuicios y las opiniones forman entonces una proyección de sentido que las sucesivas lecturas contrastan y depuran. El principio es que "el todo debe entenderse desde lo individual, y lo individual desde el todo." 31

\footnotetext{
${ }^{29}$ Ibid. Págs. 376-377. Cursivas en el original.

${ }^{30}$ GADAMER, Hans-Georg: El problema de la conciencia histórica, ed. cit. Pág. 43. Cursivas en el original.

${ }^{31}$ GADAMER, Hans-Georg: Verdad y Método II, Sígueme, Salamanca, 2006. Pág. 63.
} 
Posteriormente, Gadamer afirma que hay que ampliar en círculos concéntricos la unidad de sentido, estableciendo que la anticipación primera se hace comprensión "cuando las partes que se definen desde el

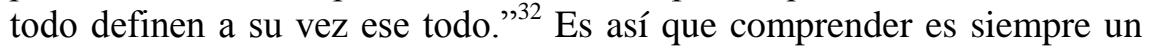
proyecto.

Ahora bien, el intérprete no está instalado en su prejuicio, más bien lo pone a prueba, por eso es un deber de la comprensión elaborar los esquemas correctos y adecuados, es decir, aventurar hipótesis apropiadas que habrán de ser contrastadas con las cosas.

Al afrontar el texto se establece "una polaridad entre familiaridad y extrañeza," 33 es decir, una especie de punto intermedio entre la objetividad de la historia y la pertenencia a una tradición. Es por esto que la hermenéutica no puede transportarnos a la esfera anímica del autor, ni la comprensión es una comunión misteriosa de las almas, como hemos dicho, sino la participación en el significado común.

De la misma manera, el intérprete ha de dirigirse a los textos examinando su origen y validez; no podemos suponer que lo que se nos dice desde un texto pueda integrarse en las propias opiniones y expectativas ni que las opiniones puedan ser entendidas de manera arbitraria; se exige cierta apertura a la opinión del otro o a la del texto mismo. Gadamer destaca: "El que quiere comprender un texto tiene que estar en principio dispuesto a dejarse decir algo por él. Una conciencia formada hermenéuticamente tiene que mostrarse receptiva desde el principio para la alteridad del texto." 34

\section{La lectura orientada a la comprensión}

Intentaremos ahora llevar al ámbito metodológico los conceptos a que nos hemos referido, de manera que pueda evidenciarse la relación de los postulados teóricos, primero con la dimensión didáctica y en un último momento con el ámbito del acompañamiento.

\footnotetext{
${ }^{32} \mathrm{Ibid}$.

${ }^{33}$ Ibid. Pág. 68.

${ }^{34}$ GADAMER, Hans-Georg: Verdad y Método, ed. cit. Pág. 335.
} 
Primeramente, postularemos tres principios generales que, bajo nuestra óptica, pueden regir toda lectura orientada a la comprensión. Después, estableceremos una serie de políticas de acción, cuya función sería la de facilitar la traducción de los postulados en acciones concretas. Sin embargo, más que momentos de un método cerrado llamo a estas últimas políticas reconociendo que el establecimiento de una estrategia $u$ otra dependerá, en realidad, de circunstancias precisas y que la operatividad del ejercicio debe ser congruente con ellas.

Los principios generales podrían ser:

(1) No es posible la comprensión absoluta del autor. Es decir, no hay verdades unívocas ni la sabiduría puede concentrarse en un solo sentido. Por el contrario, el conocimiento de algo supone siempre el desconocimiento de algo más y no existe una cultura, ni racionalidad, ni sabiduría total. En el terreno del acompañamiento o asesoramiento personal, será también muy saludable establecer este principio, sobre todo en la consideración del otro como texto y la imposibilidad de un tutor o asesor para resolver, por sí mismo, una problemática.

(2) El proceso de la comprensión no busca una comunión misteriosa de almas sino participación en el sentido común. Esto es posible gracias al diálogo y al ejercicio de la traducción en el marco de la hermenéutica filosófica. En mi perspectiva, esto supone un grado de implicación en el diálogo que pone en juego los propios prejuicios y tradición. En otras palabras, el tutor no es una entidad neutra ni imperturbable y esto es algo que tiene que considerarse.

(3) En la pluralidad de lo opinable, no todo es posible. La interpretación tiene límites que provienen del reconocimiento del primer principio y las características concretas del objeto de la comprensión. Por lo demás, los límites se aplican a ambas partes de la relación de diálogo.

Las políticas de acción, mucho más cercanas al ejercicio, tanto en la lectura como en el diálogo, podrían ser:

(i) Generar familiaridad o extrañeza. En el aula o en la tutoría no podemos esperar a que ésta surja por sí sola. Puede generarse la familiaridad en el encuentro, destacando lo común, o la extrañeza, haciendo hincapié en el asombro o maravilla de un tema o de un acontecimiento, lo importante es que este es el principio del círculo hermenéutico. 
(ii) Leer siempre primero en privado, en el entendido de que el todo debe entenderse desde lo individual y lo individual desde el todo. Generar familiaridad o extrañeza no debiera suponer que la primera lectura es conducida por el profesor o el problema a tratar en tutoría propuesto por él, por el contrario, su labor es más la de un espejo que refleja al otro para que éste se pueda contemplar con su propio estupor, y la de un facilitador de los recursos que allanen su proceso de reflexión.

(iii) Destacar la expectativa de sentido que el primer acercamiento con el texto provoca. Hacer partícipe al otro, como estudiante o como tutorado, de los procesos que él mismo protagoniza.

(iv) Evidenciar el proyecto que supone en el lector la hipótesis anterior y acompañar la confirmación o negación de la expectativa, depurando los prejuicios y ofreciendo herramientas que permitan al lector la comprensión progresiva, en círculos concéntricos, de sentido. La construcción de un autor y lector modelo puede ser una herramienta que ponga a prueba el proyecto y perfeccione la comprensión.

(v) Finalmente, el proceso se realiza a través de la pregunta y el diálogo.

\section{Diálogo y pregunta}

El diálogo con un texto supone una gran variedad de preguntas, no sólo sobre lo que el autor quiso decir o el contenido del texto, sino sobre la validez de la pregunta misma. En todo caso, en un ejercicio concreto, unas y otras se irán intercalando conducidas por el criterio del asesor.

Lo cierto es que la dialéctica del preguntar es una condición para la interpretación; sólo por medio de la pregunta se arriba a la comprensión. En adición, la lectura será más o menos relevante si la comprensión, es decir, el conjunto de preguntas que orientan su interpretación, conecta con nuestro propio horizonte vital.

Un principio práctico es que las preguntas se sucedan en dificultad, de las más simples a las más complejas primero, y alternándose unas y otras después, para evitar los silencios cuando estos no significan perplejidad sino incapacidad. 
Por otro lado, hay que tener presente que en la raíz del fenómeno de la comprensión radica el asombro y el reconocimiento de la propia ignorancia, no las respuestas establecidas de antemano, por eso debieran evitarse las preguntas retóricas o las que se formulan como afirmación personal. Siendo la pregunta el elemento que detona la curiosidad y provoca el deseo de saber, estas debieran estar siempre orientadas al conocimiento.

En la perspectiva de Gadamer, la pregunta coloca lo preguntado bajo una determinada perspectiva en la que lo más importante es seguir preguntando. Saber preguntar significa mantener en pie las preguntas, es el arte de pensar y llevar una auténtica conversación, ponerse bajo la dirección del tema sobre el que se orientan los interlocutores con amplia apertura. En el trabajo que cité al inicio del texto comparto una estrategia que suelo llamar «mejor, pregunta»o sucesión de preguntas una actividad en la que los alumnos deben responder con preguntas a las preguntas previas, motivando así la profundización y la indagación de nuevos sentidos. ${ }^{35}$ Plantear una pregunta a una pregunta previa nos acerca, también, al sentido de la pregunta original que sería el culmen de la comprensión. Y es que, para Gadamer, un texto se comprende cuando se ha comprendido la pregunta para la que fue una respuesta, lo que no es una tarea fácil; hay que reforzar lo dicho desde la cosa misma, en un verdadero recuerdo de lo originario, retrocediendo con las preguntas para poder así alcanzar el más allá. Por ello, la tarea de comprender se orienta en primer término al sentido.

Por lo demás, el arte de la pregunta supone que no se aplasta al otro con los argumentos, sino que se aprecia, por el contrario, el peso objetivo de su opinión. ${ }^{36}$

\section{Resistencias y orientación práctica}

Tristemente, el estudiante común no está habituado a buscar las preguntas o a mantener el primado del diálogo abierto. La sociedad nos ha

\footnotetext{
${ }^{35}$ Cf. MANDUJANO ESTRADA, Miguel, op. cit. Pág. 65. El ejercicio está inspirado también en los talleres de Óscar Brenifier sobre la pregunta en el aula como ejercicio filosófico.

${ }^{36}$ Cf. Ibid. Pág. 445.
} 
acostumbrado a las respuestas correctas previamente pensadas. Además, no es inusual que los problemas con la lectura de textos filosóficos comiencen mucho antes de la lectura, anclados en la sospecha legendaria que pesa sobre la filosofía en la educación media y superior, la de ser una disciplina de poca utilidad y demasiado interés teórico.

Sin embargo, aun el interés teórico-filosófico no es un ejercicio alejado de la realidad cotidiana, tampoco es el mundo que lo rodea un entorno filosóficamente hostil o ineludiblemente incomprensivo. El filósofo, incardinado en un contexto con el que mantiene una relación necesaria, no sólo se desarrolla en medio de tal situación sino que, de alguna manera, es en la situación donde surge una reflexión u otra; es decir, la actividad filosófica también pertenece a una experiencia vital.

Precisamente, aun en la estela hermenéutica es posible insistir en la unidad teoría-praxis de la filosofía práctica. En su Autopresentación, Gadamer afirma:

Lo que yo enseñaba era sobre todo la praxis hermenéutica. Esta es ante todo una praxis, el arte de comprender y de hacer comprensible. Es el alma de toda enseñanza de la filosofía. Hay que ejercitar sobre todo el oído, la sensibilidad para las predefiniciones, los preconceptos y presignificaciones que subyacen en los conceptos ${ }^{37}$

La hermenéutica no es, pues, el marco de lo extra-histórico, por el contrario, la realización de la comprensión supera cualquier historicismo. Lo que es común a todo comprender es "que la comprensión no es nunca un comportamiento subjetivo respecto a un «objeto» dado, sino que pertenece a la historia efectual, esto es, al ser de lo que se comprende." 38 La comprensión, eso sí, es una tarea necesitada de dirección metodológica.

En cuanto a la dificultad cultural que enfrenta la filosofía en los currículos obligatorios, pre y universitarios, estos se deben a un conjunto de circunstancias de muy distinta índole a las que no podemos dar razón en este trabajo. Sí nos atrevemos a afirmar que la actitud hermenéutica, es decir, el énfasis en el desarrollo del oído y la sensibilidad a que Gadamer se refiere, es un trabajo que reporta beneficios y matiza el

\footnotetext{
${ }^{37}$ GADAMER, Hans-Georg: Verdad y Método II, ed. cit. Pág. 389.

${ }^{38}$ GADAMER, Hans-Georg: Verdad y Método, ed. cit. Págs. 13-14.
} 
desinterés o rechazo de los unos con el desarrollo de las capacidades y, mejor, las actitudes de la comprensión de muchos otros que se enriquecen de esta forma de filosofía práctica y cotidiana.

Sin duda, el arte de comprender y hacer comprensible reporta múltiples y diversos beneficios que pueden ir desde lo personal hasta lo profesional, pues la esfera del sentido, vértice de la comprensión, es tan amplia como la naturaleza lingüística del hombre, en la que hemos fundamentado su posibilidad y alcance.

\section{Lectura y acompañamiento personalizado}

La relación lector-texto en la que hemos abundado puede trasladarse a la relación del acompañamiento individual o asesoramiento personalizado en dos grandes sentidos. En el primero, el tutor es un lector en diálogo con un texto que es la experiencia del alumno. En el segundo, el tutor es un facilitador que auxilia al alumno en la comprensión del otro y de su propia experiencia, es decir, que lo asiste en la tarea de convertirse en un mejor lector e intérprete de su propio mundo. Ambas relaciones guardan un cariz ético que tutela que una relación entre iguales no sea instrumentalizada.

Al respecto, Gadamer afirma que la relación yo-tú es reflexiva y no inmediata, de manera que está siempre presente la posibilidad de que reflexivamente se salte de una a la otra parte de la relación. El tú es comprendido -anticipado y aprehendido-, desde la posición del otro, tal como sucede en la conciencia histórica: En la hermenéutica, el que rompe reflexivamente la relación vital con la tradición destruye su verdadero sentido, así mismo, en la dimensión práctica, quien se sale reflexivamente de la reciprocidad de la relación yo-tú, la altera y destruye su vinculatividad moral. ${ }^{39}$ Por ello, la filosofía práctica "exige del que aprende la misma referencia indisoluble a la praxis que del que enseña." 40 En el mismo sentido, Gadamer insiste en que lo más importante es la

\footnotetext{
${ }^{39}$ Cf. Ibid. Pág. 437.

${ }^{40}$ GADAMER, Hans-Georg: "Hermenéutica como filosofía práctica", en Revista de filosofía, número 110, México, 2004. Pág. 10. Cursivas en el original.
} 
relación objetiva, que es la relación "entre la afirmación del texto y nuestra propia comprensión de la cosa." $" 41$

El tutor o asesor debiera tener especial cuidado en no realizar ese salto reflexivo de manera que se instrumentalice la presencia del otro, concretamente, tomándolo como un cliente-objeto, dicho así para enfatizar el sentido peyorativo del término. Esto sucede, por ejemplo, cuando caemos en la tentación de realizar un diagnóstico que impide un diálogo honesto y gratuito y que tiende a conducir al otro a través de una suerte de tratamiento premeditado, en lugar de abrir el camino de la comprensión a través de la puesta en juego del propio prejuicio en el diálogo.

Algunas herramientas que el alumno tutorado llegue a poner en práctica pueden morder el mismo señuelo, sobre todo si se aplican maquinalmente y sin la reflexión que conduce a ellas. Habrá, por supuesto, cuestiones más bien metodológicas que no requieran de mayor diálogo, pero según estén implementadas para abordar defectos puntuales previamente tratados.

Es decir, no sólo la lectura o la traducción como metáforas del encuentro con el otro guardan un sentido hermenéutico, ante todo, hay en el acompañamiento un principio dialógico anclado en la capacidad lingüística general. En este gran marco, la tutoría puede entenderse como una fusión de horizontes en la que la tradición y los prejuicios de los actores confluyen y construyen, a través del diálogo, una perspectiva de sentido, de interpretación de la realidad o de comprensión de la propia vida.

El proceso está mediado no sólo por la pregunta sino por la apertura de ambos sujetos, cada uno un otro para el otro, en una relación desigual por la experiencia pero igual por la condición. Por lo demás, el tutor también se involucra en el diálogo, venciendo la tentación de saltar sobre el alumno, no sólo por consideración ética sino por praxis filosófica. La praxis filosófica también requiere de coherencia y radicalidad.

A propósito, cuando a Gadamer le preguntaron ¿qué es praxis? contestó: "praxis es comportarse y actuar con solidaridad. Y la solidaridad es la condición decisiva y la base de toda razón social." ${ }^{42}$

\footnotetext{
41 "Ibid." Pág. 14.

${ }^{42}$ GADAMER, Hans-Georg: La razón en la época de la ciencia, Alfa, Barcelona, 1981. Pág. 57. Mis
} 
En adición, la hermenéutica exige una continua actitud crítica, no sólo porque la comprensión la produzca, sino porque cada vez que nos abrimos a la comprensión del otro, entramos en juego con nosotros mismos, es decir nos criticamos a nosotros mismos. Este es el principio, dice Gadamer, de una civilización libre de fanatismo y de violencia. ${ }^{43}$

El otro sentido a que podemos referirnos es en el que el tutor o acompañante realiza las veces de facilitador de la comprensión del alumno tutorado, no sólo como un lector frente al texto, sino como un entrenador que, a través de la práctica, asiste al chico en la labor de ser un lector modelo de su propio texto-experiencia del mundo.

Esta segunda posibilidad obvia la inexistencia de un autor modelo, pues no considera que alguna especie de voluntad superior modele la vida del alumno, más bien subraya el estupor y la actitud lectora del intérprete, orientando su ejercicio a la comprensión de sí mismo. El alumno debe, desde esta perspectiva, evitar saltar reflexivamente sobre su propia experiencia, es decir, evitar manipular su realidad y enfrentarla, antes bien, lo más objetivamente posible, en el sentido gadameriano de la objetividad, es decir, como la relación entre la afirmación del objeto y su propia comprensión de él. ${ }^{44}$

Finalmente, si bien la práctica de la comprensión es ya actividad, también es cierto que la interpretación - del otro, del mundo o de uno mismo-, incrementa las posibilidades de la acción, mostrándonos que las relaciones teoría-praxis no siguen la secuencia pretendida por el estatuto de la ciencia moderna y el conocimiento oficial. En el mismo orden de ideas, hay que tener presente que la interpretación no se realiza de una vez para siempre, y que la comprensión está abierta a ulteriores y progresivos descubrimientos, decíamos, de forma circular y profunda sobre los textos abiertos.

cursivas.

${ }^{43}$ Cf. VATTIMO, Gianni, Le mezze verità, La Stampa, Torino, 1988. Pág. 96.

${ }^{44}$ Cf. Supra, nota 41. 


\section{Conclusiones}

En el planteamiento de este trabajo hemos considerado la lectura como un principio hermenéutico facultado por la naturaleza lingüística del hombre. La relación didáctica-acompañamiento individual que hemos hecho en este marco, no es sólo una manera de decir, por el contrario, parte del reconocimiento de una estructura común, la de la comprensión, que ilumina -en una perspectiva o en otra- el camino del sentido.

Las experiencias de traducción, una de las figuras que mejor representan la estructura de la comprensión, demuestran el amplio espectro del fenómeno hermenéutico, ya sea en el ámbito literario, propiamente hermenéutico, o incluso social, a través de la traducción entre culturas o estructuras comprehensivas. En este sentido, podríamos hablar también de la traducción entre formas de hablar o generaciones, que permiten no sólo la comprensión profesor-alumno, y por supuesto tutor-tutorado, sino las de tipo sujeto-experiencia personal o yo-yo mismo.

Además, la estructura de la traducción supone la negociación de las partes como una participación en el sentido común que se logra a través del diálogo y el ejercicio de la pregunta.

El texto, como la obra de arte, sea el texto escrito o la propia experiencia humana, puede verse como una obra abierta, un quehacer constante que reportará, en cada acercamiento, nuevos niveles de comprensión, que impiden hacer un canon de la interpretación de una vez y para siempre.

Sin embargo, entre las posibilidades de la interpretación, no todo es posible. Esto supone una especial atención a las notas del texto. La búsqueda de un lector y autor modelo puede ser un ejercicio que ayude a leer con claridad estas notas y medie en la interpretación.

En definitiva, tanto la lectura de textos filosóficos como el encuentro en tutoría o asesoría individual guarda una forma y finalidad hermenéutica, en la doble fusión de horizontes del lector con el texto escrito o del tutor con la vivencia del tutorado, que puede ser también, la del tutorado con su propia experiencia por sí mismo.

En la medida en que estos distintos ámbitos de la interpretación guarden una forma circular, la mayor y progresiva comprensión está 
mayormente garantizada, puesto que un resultado no se toma como una verdad buscada, sino como un nuevo punto de partida que produce asombro y nos lleva a nuevas conclusiones. Esta dimensión se aplica muy bien a la actividad académica y al terreno de la orientación racional.

Las principales herramientas serán las del diálogo y la pregunta, que responden totalmente a la estructura del fenómeno comprensivo y son las principales armas para combatir la resistencia. Se convierten, además, en ejemplos fehacientes de la relación teoría-praxis que necesita el conocimiento de nuestro tiempo y las exigencias de la justicia epistémica.

Finalmente, este trabajo también nos ha permitido insistir en la idea de que la misma enseñanza de la filosofía puede considerarse un caso de filosofía aplicada, y más aún, postular, de alguna manera, que la filosofía es siempre filosofía práctica.

\section{Bibliografía}

ECO, Umberto: Dire quassi la stessa cosa. Esperienze di traduzione, Bompiani, Milano, 2003.

Cambridge, Cambridge University Press 1997.

Interpretación y sobreinterpretación [1992], .- La estructura ausente [1968], Lumen, Barcelona, 1999. .- Lector in fabula. La cooperación interpretativa en el texto narrativo [1979], Barcelona, Lumen 2000.

Lumen, 1992. .- Los límites de la interpretación [1990], Barcelona, .- Mouse or Rat? Translation as Negotiation, Phoenix, London, 2003. .- Obra Abierta [1962], Ariel, Barcelona, 1979.

- Seis paseos por los bosques narrativos. Harvard University Norton Lectures 1992-1993 [1994], Lumen, Barcelona, 1996. Barcelona, 2000. .- Tratado de semiótica general [1976], Lumen,

GADAMER, Hans-Georg: Arte y verdad de la palabra [1993], Barcelona, Paidós 1998. 
Madrid, 1993.

.- El problema de la conciencia histórica [1958], Tecnos, .- "Hermenéutica como filosofía práctica" [1974] en Revista de Filosofía, número 110, México, 2004. Págs. 7-25. .- La razón en la época de la ciencia [1976], Alfa, Barcelona, 1981.

.- Verdad y Método [1960/1975], Sígueme, Salamanca, 2007. .- Verdad y Método II [1986], Sígueme, Salamanca, 2006. 
